\title{
Influence of surface treatments on enamel susceptibility to staining by cigarette smoke
}

\author{
Juliana do Carmo Públio ${ }^{1}$, Maria Beatriz Freitas D’Arce ${ }^{2}$, Nádia Muriano Brunharo ${ }^{3}$, Gláucia Maria Bovi \\ Ambrosano ${ }^{4}$, Flávio Henrique Baggio Aguiar ${ }^{5}$, José Roberto Lovadino ${ }^{6}$, Débora Alves Nunes Leite Lima ${ }^{5}$ \\ ${ }^{1}$ DDS, MS student. Department of Restorative Dentistry, Piracicaba Dental School, Campinas University - UNICAMP, SP, \\ Brazil \\ ${ }^{2}$ DDS, MS, PhD student. Department of Restorative Dentistry, Piracicaba Dental School, Campinas University - UNICAMP, SP, \\ Brazil \\ ${ }^{3}$ DDS. Department of Restorative Dentistry, Piracicaba Dental School, Campinas University - UNICAMP, SP, Brazil \\ ${ }^{4} \mathrm{PhD}$, Full Professor. Department of Social Dentistry/Statistics, Piracicaba Dental School, Campinas University - UNICAMP, \\ SP, Brazil \\ ${ }^{5}$ DDS, MS, PhD, Assistant Professor. Department of Restorative Dentistry, Piracicaba Dental School, Campinas University - \\ UNICAMP, SP, Brazil \\ ${ }^{6}$ DDS, MS, PhD, Full Professor. Department of Restorative Dentistry, Piracicaba Dental School, Campinas University -UNI- \\ CAMP, SP, Brazil
}

Correspondence:

Department of Restorative Dentistry

Piracicaba Dental School

Campinas University - UNICAMP

PO Box 52, 13414-903

Piracicaba, SP, Brazil

jupublio@hotmail.com

Públio JC, D'Arce MBF, Brunharo NM, Ambrosano GMB, Aguiar FHB, Lovadino JR, Lima DANL. Influence of surface treatments on enamel susceptibility to staining by cigarette smoke. J Clin Exp Dent. 2013;5(4):e163-8.

http://www.medicinaoral.com/odo/volumenes/v5i4/jcedv5i4p163.pdf

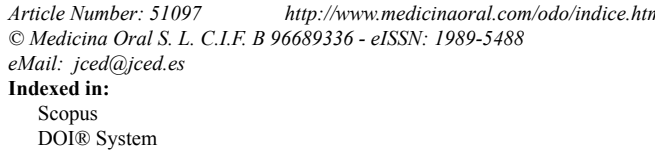

\begin{abstract}
Objectives: The purpose of this study was to evaluate the influence of remineralizing agents, including artificial saliva, neutral fluoride, and casein phosphopeptide-amorphous calcium phosphate (CPP-ACP), on the susceptibility of bleached enamel to staining by cigarette smoke.

Study design: Fifty bovine enamel blocks were randomly divided into five groups $(n=10)$ : G1- bleaching; G2bleaching and immersion in artificial saliva; G3- bleaching and application of CPP-ACP; G4- bleaching and application of neutral fluoride; and G5- untreated (Control). Teeth were bleached with 35\% hydrogen peroxide and treated with the appropriate remineralizing agent. After treatment, all groups were exposed to cigarette smoke. Enamel color measurements were performed at three different times: before treatment (T1), after treatment (bleaching and remineralizing agent) (T2), and after staining (T3), by using the CIE Lab method with a spectrophotometer. The

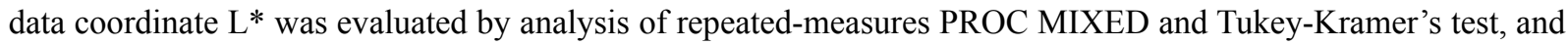
the $\Delta \mathrm{E}$ values were submitted to one-way ANOVA and Tukey's test $(\alpha=0.05)$.

Results: The G1 group did not show any statistically significant difference for $\mathrm{L}^{*}$ values between times $\mathrm{T} 1$ and T2. The G4 and G5 groups showed lower L* values at T3 compared to T2. No significant differences between the groups were observed for $\Delta \mathrm{E}$ (after treatment and staining). However, G4 showed a clinically apparent color change.

Conclusions: Treatment of bleached enamel with neutral fluoride can contribute to the increased staining of enamel due to cigarette smoke.
\end{abstract}

Key words: Spectrophotometer, remineralizing agents, bleaching. 


\section{Introduction}

Bleaching agents are used to remove intrinsic pigments from dental enamel. Common bleaching techniques include home bleaching (performed by the patient with individual trays) and in-office bleaching (performed by dentists) (1). Options for vital tooth-bleaching procedures include carbamide peroxide and hydrogen peroxide products. The most-accepted theory for the mechanism of action of bleaching agents is the oxidation of pigments in dental structures (2). Bleaching agents are thought to cleave the extensive conjugated chains that comprised the pigments (3), thereby reducing the number of pigment molecules (4).

Several studies have shown that bleached enamel can become stained after exposure to pigments, such as tea, coffee, and red wine (5-8). Some authors consider that the loss of mineral content, which causes decalcification, porosity, and topographic changes (9-11), may favor tooth staining. Attin et al. (11) concluded that mineral loss is compensated for by the remineralization property of saliva, which contains calcium and phosphate ions. Furthermore, the stain absorption is related to the $\mathrm{pH}$, composition, and temperature at which the pigments are exposed.

Although there have been numerous studies of bleaching treatment effectiveness and its adverse effects on tooth enamel and adjacent tissues, there are no reports in the literature about the behavior of newly whitened teeth exposed to cigarette smoke. Thus, the objective of this study was to evaluate the color change of bovine enamel fragments that were bleached with $35 \%$ hydrogen peroxide, subjected to different surface treatment protocols (i.e., with saliva, fluoride, or casein phosphopeptideamorphous calcium phosphate [CPP-ACP]), and then exposed to cigarette smoke.

\section{Material and Methods}

Fifty bovine incisors were stored in $0.1 \%$ thymol after collection and disinfection. The teeth were examined under a light microscope (4×) (Carl Zeiss Zeiss-Brazil) for the presence of any irregularities, such as cracks or stains, that would interfere with the research results. If these features were found, then the tooth was discarded and replaced. The teeth were stored in distilled water under cooling until the moment of their use. Fifty dental blocks were extracted from a $5 \times 5 \mathrm{~mm}$ area of the buccal surface of the bovine incisors through two cuts in the mesio-distal and two cuts in the cervical-incisal directions by using a double-faced diamond disc (EXTEC Diamond Wafering Blade, $102 \times 12.7 \times 0.3 \mathrm{~mm}$ ) in a water-cooled diamond saw (IsoMet 1000, Buehler, Lake Bluff, IL, USA). The dentin and enamel surfaces were flattened with \#600 and \#1200 grit silicon carbide (SiC) paper, in a polishing machine (Arotec Ind. Com., Cotia, SP, Brazil) under constant water irrigation, to ob- tain a 3-mm-thick block ( $2 \mathrm{~mm}$ of dentin and $1 \mathrm{~mm}$ of enamel). In the interval between each application of $\mathrm{SiC}$ paper and at the end of the process, the specimens were cleaned with distilled water in an ultrasonic bath (T7 Type, CT Model, Thornton-Inpec electronic Ltd, Vinhedo, SP, Brazil) for debris removal. Each specimen was marked with a diamond bur \#1012 (KG Sorensen) on one side, to standardize the sample position in the spectrophotometer (Konica Minolta CM 700d, Japan). The specimens were stored in artificial saliva for 24 hours (12) and maintained at $37 \pm 2{ }^{\circ} \mathrm{C}$. Samples were randomly divided into five groups $(n=10)$, according to the treatment protocol.

\section{- Treatment Protocol}

Bleaching: Bleaching with $35 \%$ hydrogen peroxide (HP) (Whiteness HP Maxx 35\% - FGM, Santa Catarina, Brazil) was performed according to the manufacturer's instructions. Bleaching agent was applied three times for 15 minutes each to the enamel surface. The specimens were then washed thoroughly in running water.

Surface treatment: After bleaching, one of the following surface treatments was performed to each sample group: Group 1: Samples were submitted to the bleaching protocol and no surface treatment; Group 2 (Artificial Saliva): Samples were immersed in artificial saliva for 30 minutes; Group 3 (CPP-ACP): CPP-ACP paste (MI Paste, GC) was applied to the enamel surface at low speed with a polishing rubber mounted on the handpiece. After 3 minutes, excess paste was removed by air-water spray for 10 seconds; Group 4 ( $2 \%$ Neutral Fluoride): Neutral fluoride was applied to the enamel surface for 4 minutes, and excess fluoride was removed by a cotton-tipped flexible plastic (Swabs, Johnson \& Johnson, Brazil); Group 5 (Control): No bleaching or surface treatment was performed; this group was maintained at $37 \pm 2{ }^{\circ} \mathrm{C}$ in artificial saliva during the experiment.

Exposure to cigarette smoke: Samples were fixed in a device and positioned in a machine to simulate smoke inhalation. The samples remained in contact with the cigarette smoke while cigarettes were burned. Each sample underwent 10 cycles of simulated smoke exposure. The samples were cleaned on each side with a mixture of pumice and water by a polishing rubber mounted at low speed for 30 seconds each side and washed in running water by a single operator. Excess water was removed with absorbent paper before color measurement.

\section{- Color Measurements}

Before the color analysis stage was performed for the first time, specimens with similar means were selected and outliers were discarded, to standardize the specimens. Color measurement was performed three times: before bleaching (Initial), after bleaching and surface treatment (After Bleaching), and after exposure to cigarette smoke (After Staining). Specimens were placed in a Teflon device (sample holder) inside a light cabin (GTI Mini Mat- 
cher MM1e, GTI Graphic Technology Inc., Newburgh, NY, USA) to standardize the ambient light during the measurement process. The samples were assessed with a previously calibrated spectrophotometer Konica Minolta CM-700d (Konica Minolta Investment Ltd. Sensing Business Division, Shanghai, China), which was used in accordance with the manufacturer's instructions.

Spectrophotometric values were quantified on the CIE Lab system as three coordinates $\left(L^{*}, a^{*}, b^{*}\right)$ that define the color of an object within a three-dimensional color space. A microcomputer with the On Color QC Lite software (Konica Minolta, Japan) was used to generate spectral measurements as a function of wavelength for data-processing and analysis. In the color space, $L^{*}$ indicates lightness $(\mathrm{L}+=$ lightness and $\mathrm{L}-=$ darkness $), \mathrm{a}^{*}$ coordinate represents the red/green range $\left(\mathrm{a}^{*}+=\right.$ redness and $\mathrm{a}^{*-}=$ greenness) and the $\mathrm{b}^{*}$ coordinate represents the yellow/blue range $\left(b^{*+}=\right.$ yellowness and $b^{*}=$ blueness). The values of the coordinates $a^{*}$ and $b^{*}$ approach zero, indicating neutral colors (white and gray) and an increase in magnitude for more saturated or intense colors $(3,24)$. The $\mathrm{L}^{*} \mathrm{a} * \mathrm{~b} *$ system provides the numeric definition of a color and the difference between two colors with the following formula: $\Delta \mathrm{E}=\left[\left(\mathrm{L}_{1}-\mathrm{L}_{0}\right)^{2}+\left(\mathrm{a}_{1}-\mathrm{a}_{0}\right)^{2}\right.$ $\left.+\left(b_{1}-b_{0}\right)^{2}\right]^{1 / 2}$.
After exploratory data analysis, the $\mathrm{L}^{*}$ variable was subjected to analysis using the methodology of mixed models for repeated-measures by PROC MIXED procedure of SAS statistical software. The treatment means were compared using Tukey-Kramer's test, considering a 5\% significance level. The variables $\Delta \mathrm{E} 1, \Delta \mathrm{E} 2$ and $\Delta \mathrm{E} 3$ were explored by one-way analysis of variance (ANOVA) and Tukey's test at a significance level of 5\%.

- Scanning Electron Microscopy (SEM) Analysis

After the bleaching and surface treatments, three samples from each group were randomly selected, dehydrated by immersion in increasing alcohol concentrations, and sputter-coated with gold for SEM analysis (JEOL JSM-5600 LV, Tokyo, Japan).

\section{Results}

\section{- Color Analysis}

Table 1 shows the average (mean and standard deviation) values for $\mathrm{L}^{*}(\mathrm{~L}=100$ - lightness; $\mathrm{L}=0$ - darkness).

Table 2 shows the color variation $(\Delta \mathrm{E})$ between treatment sessions: After Bleaching $\times$ Initial $(\Delta \mathrm{E} 1)$, After Staining $\times$ After Bleaching $(\Delta \mathrm{E} 2)$, and After Staining $\times$ Initial $(\Delta \mathrm{E} 3)$.

Table 1. Mean and standard deviation (SD) of $\mathrm{L} *$ values as a function of treatment and time.

\begin{tabular}{lccc}
\hline \multirow{2}{*}{ Treatment } & \multicolumn{3}{c}{ Time } \\
\cline { 2 - 4 } & \multicolumn{1}{c}{ Initial } & After bleaching & After staining \\
\hline Bleaching+Smoke & $81.92(1.18) \mathrm{Ba}$ & $84.02(1.76) \mathrm{Aa}$ & $84.84(1.54) \mathrm{Aa}$ \\
Bleaching+Saliva+Smoke & $81.81(1.75) \mathrm{Ba}$ & $83.73(1.97) \mathrm{Aab}$ & $85.05(1.81) \mathrm{Aa}$ \\
Bleaching+CPP-ACP+Smoke & $81.39(1.49) \mathrm{Ba}$ & $82.58(1.51) \mathrm{Aab}$ & $82.27(0.92) \mathrm{Ab}$ \\
Bleaching+Fluoride+Smoke & $81.34(1.62) \mathrm{Ba}$ & $82.98(1.58) \mathrm{Aab}$ & $80.64(2.07) \mathrm{Bbc}$ \\
Control+Smoke & $81.34(1.62) \mathrm{Aa}$ & $81.40(1.63) \mathrm{Ab}$ & $78.73(1.86) \mathrm{Bc}$ \\
\hline
\end{tabular}

Means followed by different letters (uppercase letters in the lines and lowercase letters in the columns) indicate statistical differences $(\mathrm{p} \leq 0.05)$. $\mathrm{CPP}-\mathrm{ACP}=$ "casein phosphopeptide-amorphous calcium phosphate".

Table 2. Mean and standard deviation (SD) of $\Delta \mathrm{E}$.

\begin{tabular}{lccl}
\hline Treatment & $\Delta \mathrm{E} 1$ & $\Delta \mathrm{E} 2$ & $\Delta \mathrm{E} 3$ \\
\hline Bleaching+Smoke & $2.44(0.72) \mathrm{a}$ & $2.80(1.02) \mathrm{a}$ & $4.75(0.74) \mathrm{a}$ \\
Bleaching+Saliva+Smoke & $2.52(0.96) \mathrm{a}$ & $2.57(0.68) \mathrm{a}$ & $4.91(0.98) \mathrm{a}$ \\
Bleaching+CPP-ACP+Smoke & $1.36(0.57) \mathrm{b}$ & $2.93(0.77) \mathrm{a}$ & $3.59(1.04) \mathrm{ab}$ \\
Bleaching+Fluoride+Smoke & $2.60(1.03) \mathrm{a}$ & $3.61(0.97) \mathrm{a}$ & $3.82(1.22) \mathrm{ab}$ \\
Control+Smoke & $0.52(0.51) \mathrm{b}$ & $2.87(1.83) \mathrm{a}$ & $3.10(1.86) \mathrm{b}$ \\
\hline
\end{tabular}

Means followed by different letters columns differ $(p \leq 0.05)$

$\Delta \mathrm{E} 1=$ "After Bleaching $\times$ Initial"

$\Delta \mathrm{E} 2=$ "After Staining $\times$ After Bleaching "

$\Delta \mathrm{E} 3=$ "After Staining $\times$ Initial". CPP-ACP = "casein phosphopeptide-amorphous calcium phosphate". 


\section{- Scanning Electron Microscopy}

Photomicrographs of the surfaces treated with $35 \%$ HP (G1) showed changes in the enamel morphology, revealing many pores and erosions as well as evidence of enamel rods (Fig. 1), compared to the control group (G5) (Fig. 1). Surfaces treated with artificial saliva (G2) had fewer pores and depressions but evidence of many enamel rods (Fig. 2). Photomicrographs of the CPPACP (G3) samples showed slight surface morphological changes (Fig. 2). Surfaces treated with $2 \%$ neutral fluoride (G4) (Fig. 2) displayed pores and depressions that were smaller than those of the G1 samples.
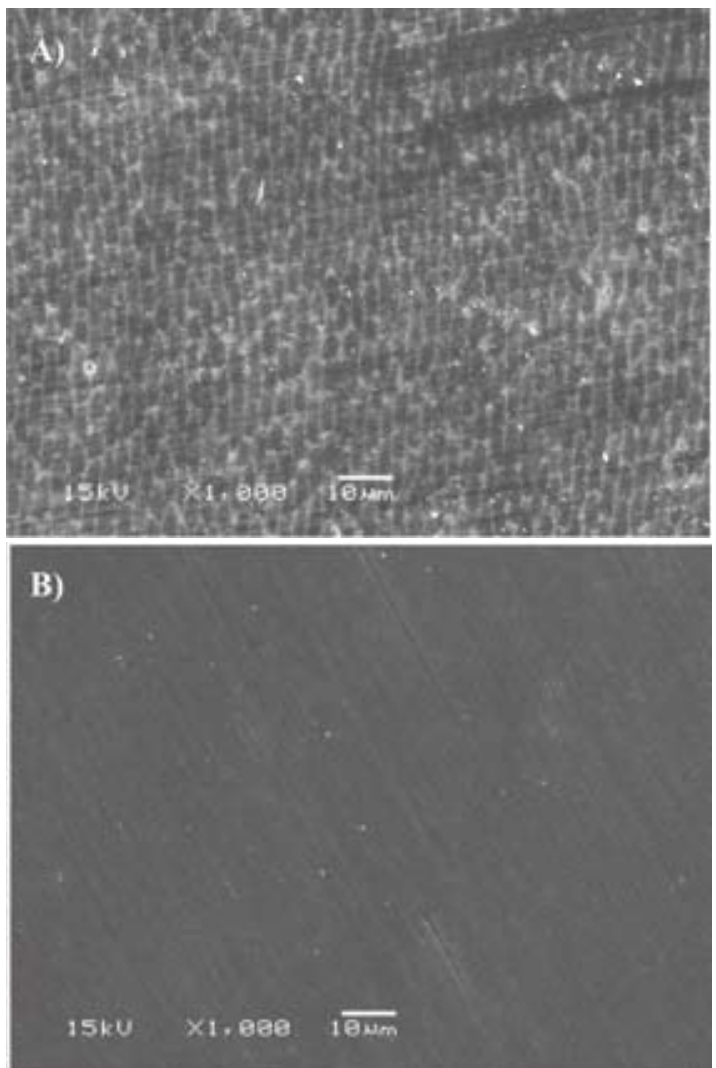

Fig. 1. SEM observation: A) Bleaching + Smoke, B) Control + Smoke, at $1000 \times$ magnification.

\section{Discussion}

In this study, at the After Staining time, the G4 (Bleaching + Fluoride + Smoke) and G5 (Control + Smoke) groups showed the lowest L* means (highest staining), which differed from those at the After Bleaching time. The G1 (Bleaching + Smoke) and G2 ("Bleaching + Saliva + Smoke) groups showed less staining (highest $\mathrm{L}^{*}$ means) at the After Staining time compared to the other groups.

Neutral fluoride has been used after bleaching treatment to contribute to enamel remineralization (13). According to Reynolds et al. (14), the capacity of fluoride to promote
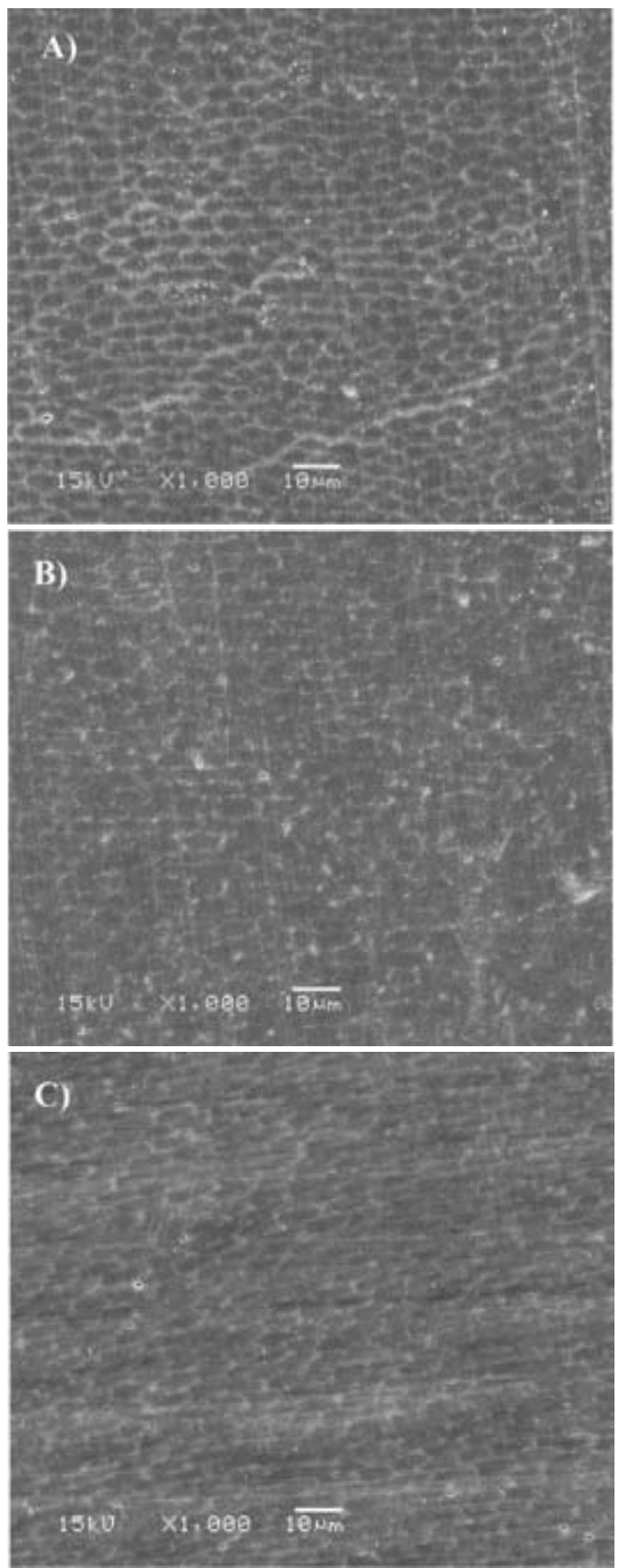

Fig. 2. SEM observation: A) Bleaching + Saliva + Smoke; B) Bleaching + CPP-ACP + Smoke; C) Bleaching + Fluoride + Smoke, at $1000 \times$ magnification.

dental tissue remineralization is linked to the availability of calcium and phosphate ions in the environment. Fluoride ions may guide tissue remineralization if adequate amounts of calcium and phosphate ions are still available in the saliva or dental biofilm (15). Therefore, after fluoride application, the enamel must be exposed to saliva for sufficient time to enable the appropriate saturation of ions to allow for fluorapatite or fluorohydroxyapatite generation on the enamel surface. The microporosities formed after the bleaching treatment and fluoride application were not homogeneously remineralized, which 
allowed the stain to develop on the enamel surface after cigarette smoke exposure. According to Ferreira et al. (16), fluoride application did not prevent morphological changes on enamel after dental bleaching.

CPP-ACP is another compound that has been used as a remineralizing agent because of its ability to release calcium and phosphate ions in the tooth surface (17). CPP-ACP consists of titanium dioxide, a pigment that is widely used by several industries for its brightness, high refractive index, discoloration resistance (18), and ability to opacify and bleach the environment in which it is dispersed, as described by the manufacturer. This last property of titanium dioxide may have made the enamel surface lighter, which may have interfered with the degree to which the smoke stains were covered up in the final color measurement. In particular, there was no statistical difference for the group treated with CPPACP between the after-bleaching and after-staining times, although the CPP-ACP and fluoride groups showed lower $\mathrm{L}^{*}$ means when compared to the other groups. The SEM analyses of surfaces bleached and treated with CPP-ACP paste are consistent with the findings of Cunha et al. (19), who also observed small irregularities on the enamel surface.

The "Bleaching" (G1) and "Saliva + Bleaching" (G2) groups showed the highest $\mathrm{L}^{*}$ means compared to the other groups. The $\Delta \mathrm{E}$ means for these two groups, comparing the overall color change between "After Staining $\times$ Initial" $(\Delta \mathrm{E} 3)$ in Table 2 , were also the highest means showing a statistically significant result, because the results with the CPP-ACP and fluoride treatments did not differ from the final means. According to Cavalli et al. (20), as a remineralizing solution, saliva repairs the tooth surface microstructures through the absorption and precipitation of salivary calcium and phosphate ions. In an in vitro study, Liporoni et al. (21) also observed that storage in artificial saliva can promote a lower amount of staining of the dental surface, due to its remineralizing potential.

The photomicrographs of enamel treated with 35\% HP revealed an irregular pattern in the exposure of enamel rods (Fig. 1). This microporosity of bleached enamel is caused by the degradation of the organic material (22, 23), which is independent of the gel $\mathrm{pH}$ (24). Ferreira et al. (16) observed by SEM that a 35\% HP bleaching agent causes porosity, irregularities, and depressions on the tooth surface. Although these superficial changes are clinically imperceptible (25), several studies have shown that they can favor pigment accumulation that would interfere with the longevity of dental bleaching. In this study, the enamel surfaces were subjected to prophylaxis after cigarette smoke exposure, to simulate the clinical condition. Prophylaxis may have led to the removal of the demineralized area and, possibly, the pigmented enamel, which could explain why the bleached surface was not pigmented after smoke exposure.

The CPP-ACP and neutral fluoride treatments did not prevent the accumulation of pigments on remineralized enamel surfaces when these surfaces were exposed to cigarette smoke. Even though CPP-ACP promotes the absorption and precipitation of calcium and phosphate ions, deposition of these ions can occur in an irregular way and might increase the susceptibility to enamel staining. In an in vitro study, Singh et al. (26) observed that CPPACP and topical fluoride surface treatments prevented bleached enamel staining. However, their samples were stored in artificial saliva after surface treatment, which may explain how this result was achieved.

In conclusion, the results of this study show that bleached enamel exposed to artificial saliva for 30 minutes shows the lowest level of staining by cigarette smoke, and the treatment of bleached enamel with neutral fluoride can contribute to increase enamel staining due to cigarette smoke. Thus, after in-office dental bleaching treatment is performed for smokers, the patient should wait at least 30 minutes before smoking, to allow for the remineralization of the enamel by saliva and to avoid staining the tooth enamel.

\section{References}

1. Lewinstein I, Hirschfeld Z, Stabholz A, Rotstein I. Effect of hydrogen peroxide and sodium perborate on the microhardness of human enamel and dentin. J Endod. 1994;20:61-3.

2. McEvoy SA. Chemical agents for removing intrinsic stains from vital teeth. I. Technique development. Quintessence Int. 1989; 20:323-8.

3. Joiner A. The bleaching of teeth: a review of the literature. J Dent. 2006;34:412-9.

4. Sulieman M. An overview of bleaching techniques: I. History, chemistry, safety and legal aspects. Dent Update. 2004; 31:608-10, 612-4, 616.

5. McGuckin RS, Babin JF, Meyer BJ. Alterations in human enamel surface morphology following vital bleaching. J Prosthet Dent. 1992;68:754-60.

6. Pinto CF, Oliveira Rd, Cavalli V, Giannini M. Peroxide bleaching agent effects on enamel surface microhardness, roughness and morphology. Braz Oral Res. 2004;18:306-11.

7. Berger SB, Coelho AS, Oliveira VA, Cavalli V, Giannini M. Enamel susceptibility to red wine staining after $35 \%$ hydrogen peroxide bleaching. J Appl Oral Sci. 2008;16:201-4.

8. Setien V, Roshan S, Cala C, Ramirez R. Pigmentation susceptibility of teeth after bleaching with 2 systems: an in vitro study. Quintessence Int. 2009;40:47-52.

9. Ernst CP, Marroquín BB, Willershausen-Zönnchen B. Effects of hydrogen peroxide-containing bleaching agents on the morphology of human enamel. Quintessence Int. 1996;27:53-6.

10. Josey AL, Meyers IA, Romaniuk K, Symons AL. The effect of a vital bleaching technique on enamel surface morphology and the bonding of composite resin to enamel. J Oral Rehabil. 1996;23:244-50.

11. Attin T, Kielbassa AM, Schwanenberg M, Hellwig E. Effect of fluoride treatment on remineralization of bleached enamel. J Oral Rehabil. 1997;24:282-6.

12. Serra MC, Cury JA. The in vitro effect of glass-ionomer cement restoration on enamel subjected to a demineralization and remineralization model. Quintessence Int. 1992;23:143-7.

13. ten Cate JM. Review on fluoride, with special emphasis on calcium fluoride mechanisms in caries prevention. Eur J Oral Sci. 1997; 105:461-5.

14. Reynolds EC, Cai F, Cochrane NJ, Shen P, Walker GD, Morgan 
MV, et al. Fluoride and casein phosphopeptide-amorphous calcium phosphate. J Dent Res. 2008;87:344-8.

15. Cochrane NJ, Cai F, Huq NL, Burrow MF, Reynolds EC. New approaches to enhanced remineralization of tooth enamel. J Dent Res. 2010;89:1187-97.

16. Ferreira Sda S, Araújo JL, Morhy ON, Tapety CM, Youssef MN, Sobral MA. The effect of fluoride therapies on the morphology of bleached human dental enamel. Microsc Res Tech. 2011;74:512-6.

17. Hamba H, Nikaido T, Inoue G, Sadr A, Tagami J. Effects of CPPACP with sodium fluoride on inhibition of bovine enamel demineralization: a quantitative assessment using micro-computed tomography. J Dent. 2011;39:405-13.

18. Weir A, Westerhoff P, Fabricius L, Hristovski K, von Goetz N. Titanium dioxide nanoparticles in food and personal care products. Environ Sci Technol. 2012;46:2242-50.

19. Cunha AG, De Vasconcelos AA, Borges BC, Vitoriano Jde O, Alves-Junior C, Machado CT, et al. Efficacy of in-office bleaching techniques combined with the application of a casein phosphopeptideamorphous calcium phosphate paste at different moments and its influence on enamel surface properties. Microsc Res Tech. 2012;75:101925.

20. Cavalli V, Rodrigues LK, Paes-Leme AF, Brancalion ML, Arruda MA, Berger SB, et al. Effects of bleaching agents containing fluoride and calcium on human enamel. Quintessence Int. 2010;41:e157-65.

21. Liporoni PC, Souto CM, Pazinatto RB, Cesar IC, de Rego MA, Mathias $\mathrm{P}$, et al. Enamel susceptibility to coffee and red wine staining at different intervals elapsed from bleaching: a photoreflectance spectrophotometry analysis. Photomed Laser Surg. 2010;28:S105-9.

22. Rotstein I, Dankner E, Goldman A, Heling I, Stabholz A, Zalkind M. Histochemical analysis of dental hard tissues following bleaching. J Endod. 1996;22:23-5.

23. Cakir FY, Korkmaz Y, Firat E, Oztas SS, Gurgan S. Chemical analysis of enamel and dentin following the application of three different at-home bleaching systems. Oper Dent. 2011;36:529-36.

24. Kwon YH, Huo MS, Kim KH, Kim SK, Kim YJ. Effects of hydrogen peroxide on the light reflectance and morphology of bovine enamel. J Oral Rehabil. 2002;29:473-7.

25. Gomes MN, Francci C, Medeiros IS, De Godoy Froes Salgado NR, Riehl H, Marasca JM, et al. Effect of light irradiation on tooth whitening: enamel microhardness and color change. J Esthet Restor Dent. 2009;21:387-94.

26. Singh RD, Ram SM, Shetty O, Chand P, Yadav R. Efficacy of casein phosphopeptide-amorphous calcium phosphate to prevent stain absorption on freshly bleached enamel: An in vitro study. J Conserv Dent. 2010;13:76-9.

\section{Conflict of Interest}

The authors declare that there are no conflicts of interest that could influence their work. 